\title{
Editorial
}

\section{At the Outset}

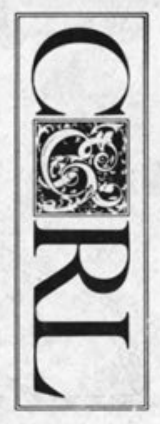

My world will never be the same again . . . for three years in any case. With this issue I assume the mantle of editor from C. James Schmidt and, through him, from Richard D. Johnson, Richard M. Dougherty, David Kaser, Maurice F. Tauber, Carl M. White, and A. F. Kuhlman. When I review this lineage, I feel obliged to acknowledge their toil and sweat and the effort that they expended to create for us the premier research journal in the field of academic librarianship.

Implicit in the image of a mantle is the fact of an obligation. The obligation that I assume is to be true to the best traditions of College \& Research Libraries. These traditions are a commitment to quality, a commitment to publishing the product of scholarly research, and a commitment to academic librarianship. "Hold true to the best" is the first of two rules I shall follow. The second rule is "Do not allow tradition to rule unilaterally." I want to stake out a commitment to present to you the best that our profession's minds can offer, whether through critical analysis, essay, or other forms of thinking that glorify the wonders of the creative mind.

As librarians we face complex situations almost daily. We should be able to look to our professional literature for guidance, for hints, and for thought-provoking judgment so that we can cope with this complexity more effectively. Personally, I have become wary, even tired, of research that fails to meet the simple criterion of "so what!" I read too many articles that offer data but not synthesis, information but not understanding.

"Do something manageable" is the advice given to many aspiring researchers and others contemplating the rigors of stringent tenure requirements. The chief characteristic of the resulting research is sometimes the fact of its existence rather than its value as a contribution to knowledge. Recently there has been an acknowledgment of a trend toward an overly narrow conceptual basis for research. Occasionally there will be an urge for robust theory or paradigm busters. Perhaps, before academic librarianship can comply with this urging, there should be a clearer sense of direction provided by library leaders about what is to be done. My own inclination is to stress quality service, innovative programs, and a general, more adaptive orientation to the problems that beset us and to the opportunities that dazzle us with their potential.

What should I do as editor? Beyond the obvious mechanics and techniques of editorial work, the answer is in your hands as prospective contributors to the professional literature. I believe that we need to challenge our assumptions, we need to improve our concept of service, and we need to alter value systems that stress things but not people.

The excitement of being editor will not come from reviewing the obvious or the well-known. It will come from being part of a future that we share together as we strive to become better librarians and better people. This is also the excitement of life. 


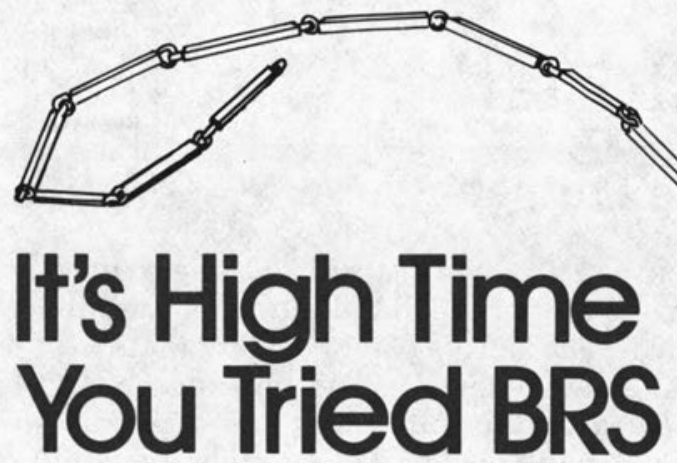

Look What's Waiting For You!

- 82 databases-37 available exclusively from BRS-give you access to timely, unique information.

- Convenient grouping of databases by major subject categories provides you with a breadth of online information.

- Simple interactive language makes BRS easy to learn and use, whether you're an online searching pro or a first-time user.

- Available when and where you need it, home or work, 22 hours every working day, plus weekend and holiday hours.

- Wide choice of access plans lets you tailor your usage to your budget.

Return the coupon for timely information on this powerful, online search service.
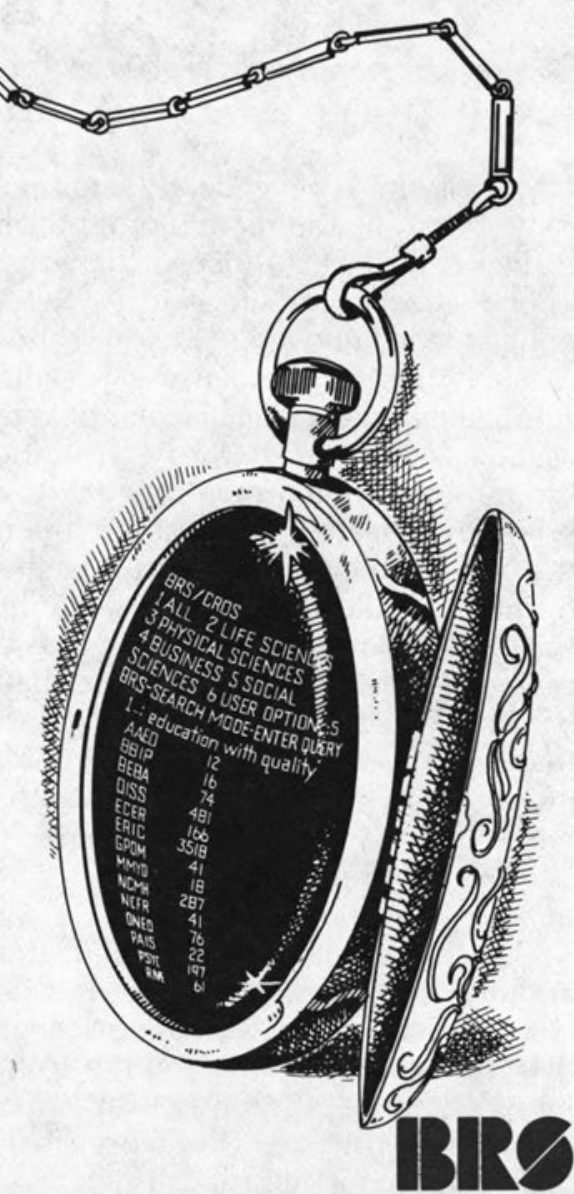

An ITG Company

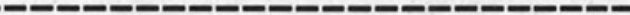

II's Time I Learned More!

$\square$ Please send details on BRS services, rates and access plans.

I'm Ready To Sign Up Now!

$\square$ Please send me the necessary forms.

Mail to: BRS, 1200 Route 7, Latham, NY 12110

NAME

COMPANY/INSTITUTION

ADDRESS

\begin{tabular}{lll}
\hline CITY STATE ZIP &
\end{tabular}

TELEPHONE ( )

CRJ $7 / 84$ 